

\title{
Solvothermal Synthesis and Crystal Structure of A Supramolecular Compound Tris(tert-butylamino)chlorophosphonium Chloride
}

\author{
Hong-Sheng Shi, Jin Qian, Jing Fan, Ni Deng and Kangying Shu*
}

College of Materials Science and Engineering, China Jiliang University, Hangzhou 310018, P.R. China

*Corresponding author: Fax: +86 571 86835740; Tel: +86 571 86835740; E-mail: scintcrystal@yeah.net

\begin{abstract}
During the research of the reaction of $\mathrm{OP}(\mathrm{NHt}-\mathrm{Bu})_{3}$ and $\mathrm{ZnCl}_{2}$ with hydrochloric acid in toluene, the crystal of the tris(tertbutylamino)chlorophosphonium chloride $\left[\mathrm{ClP}(\mathrm{NHt}-\mathrm{Bu})_{3}\right](\mathrm{Cl})(\mathbf{1})$ was obtained under solvothermal reaction condition. The single-crystal X-ray diffraction reveals the title compound crystallizes in space group $\mathrm{P} 2_{1} / \mathrm{c}$ (No. 14) with $\mathrm{a}=15.280(3) \AA, \mathrm{b}=9.2100(18) \AA$, $\mathrm{c}=$ $12.790(3) \AA, \alpha=90^{\circ}, \beta=93.19(3)^{\circ}, \gamma=90^{\circ}, V=1797.1(6) \AA^{3}, Z=4, D_{c}=1.176 \mathrm{~g} \mathrm{~cm}^{-3}, F_{(000)}=688, \mu=0.44 \mathrm{~mm}^{-1}$. The phosphorus atom of cation is located in the center of a tetrahedron constructed of a chloride atom and three $\mathrm{N}$ atoms of three NHt-Bu groups. The anion of $\mathrm{Cl}^{-}$is connected with a cation and adjacent cation through three $\mathrm{N}-\mathrm{H} \cdots \mathrm{Cl}$ hydrogen bonds. And through these hydrogen bonds, a zig-zag supramolecular chain is formed, which array all along the $\mathrm{c}$ axis.
\end{abstract}

Key Words: Solvothermal synthesis, Hydrogen bonds, Supramolecular structure.

- - - - - - - - - - - - - - - - - - - - - - - - - - - -

\section{INTRODUCTION}

The preparation and structural characterization of imido analogues of common phosphorus oxoanions is an active area of main group chemistry ${ }^{1-4}$. Chivers et al. ${ }^{5}$ found that OP(NHt$\mathrm{Bu})_{3}$ could be protonated and converted to a cation under hydrothermal condition with $\mathrm{CuCl}_{2}{ }^{5}$. Armstrong et al. ${ }^{6}$ had also investigated the reaction of $\mathrm{OP}(\mathrm{NHt}-\mathrm{Bu})_{3}$ and $\mathrm{ZnMe}_{2}$ and successfully synthesized some novel zinc cluster compounds exhibited interesting molecular structure. Being motivated these researches, we employed $\mathrm{OP}(\mathrm{NHt}-\mathrm{Bu})_{3}, \mathrm{ZnCl}_{2}$ and hydrochloric acid as reactor to synthesize novel zinc coordinated compound, but a new organic phosphorous cation compound featured as a supramolecular structure was obtained (SchemeI). During the past decades, a large number of supramolecular structures have been assembled and characterized due to their interesting structure and many respected applications in sensors, catalysis, optical/optoelectronic and magnetic materials $e t c .^{7-13}$. Here, we report the solvothermal synthesis and crystal structure of a supramolecular compound $[\mathrm{ClP}(\mathrm{NHt}-$ $\left.\mathrm{Bu})_{3}\right](\mathrm{Cl})(\mathbf{1})$.

\section{EXPERIMENTAL}

Synthesis of $\left[\mathrm{CIP}(\mathrm{NHt}-\mathrm{Bu})_{3}\right](\mathbf{C l})(\mathbf{1})$ : All chemicals were obtained from commercial sources and used as received. The title compound was synthesized by a solvothermal reaction from toluene. The solvothermal treatment of $\mathrm{ZnCl}_{2}(1 \mathrm{mmol})$

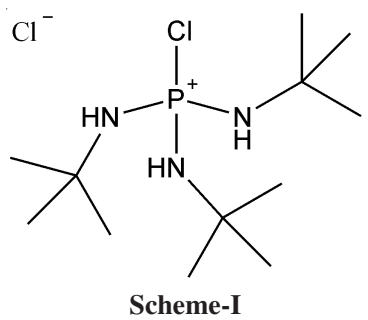

with $\mathrm{OP}(\mathrm{NHt}-\mathrm{Bu})_{3}(1 \mathrm{mmol})$ in $\mathrm{HCl}(1 \mathrm{~mL})$ and toluene $(10$ $\mathrm{mL})$ at $353 \mathrm{~K}$ for 2 days produces $\left[\mathrm{ClP}(\mathrm{NHt}-\mathrm{Bu})_{3}\right](\mathrm{Cl})$ crystals after cooling down to room temperature, yield $25 \%$ (based on $\left.\mathrm{OP}(\mathrm{NHt}-\mathrm{Bu})_{3}\right)$.

Single crystal structure determination: $X-$ Ray intensity data for 1 were collected on a black prism crystal $(0.20 \mathrm{~mm} \times$ $0.10 \mathrm{~mm} \times 0.10 \mathrm{~mm}$ ) at $153(2) \mathrm{K}$ on a Bruker P4 CCD area detector diffractometer using graphite monochromated $\mathrm{MoK}_{\alpha}$ radiation $(\lambda=0.071073 \mathrm{~nm})$. The structure was solved using direct methods and refined by full-matrix least-squares techniques. All non-hydrogen atoms were assigned anisotropic displacement parameters in the refinement. All hydrogen atoms were added at calculated positions and refined using a riding model. The structure was refined on $\mathrm{F}^{2}$ using SHELXTL97 software package without any unusual events ${ }^{14}$. The crystal and refinement details for compound $\mathbf{1}$ are listed in Table-1. The selected bond lengths and bond angles are gathered in Table-2. 


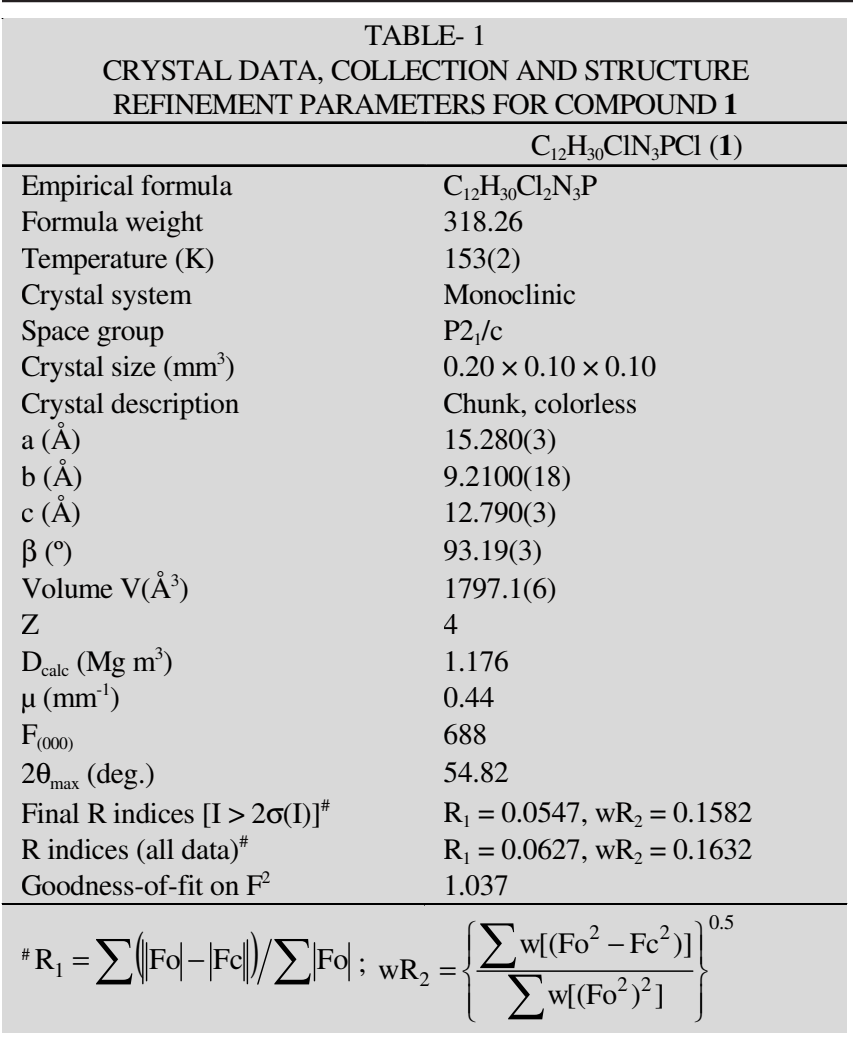

\begin{tabular}{lccc}
\multicolumn{4}{c}{ TABLE- 2 } \\
SELECTED BOND LENGTHS $(\AA)$ & AND BOND ANGLES $\left({ }^{\circ}\right)$ FOR 1 \\
\hline C11-P1 & $2.0378(11)$ & P1-N1 & $1.609(3)$ \\
P1-N2 & $1.614(3)$ & P1-N3 & $1.602(3)$ \\
N1-C1 & $1.496(4)$ & N2-C5 & $1.501(4)$ \\
N3-C9 & $1.498(4)$ & - & - \\
N1-P1-C11 & $110.41(11)$ & N2-P1-C11 & $110.51(11)$ \\
N3-P1-C11 & $100.30(10)$ & N1-P1-N2 & $102.28(14)$ \\
N3-P1-N1 & $115.80(15)$ & N3-P1-N2 & $117.71(15)$ \\
C1-N1-P1 & $130.1(2)$ & C5-N2-P1 & $130.5(2)$ \\
C9-N3-P1 & $130.1(2)$ & - & - \\
\hline
\end{tabular}

\section{RESULTS AND DISCUSSION}

We have synthesized the supramolecular compound $\left[\mathrm{ClP}(\mathrm{NHt}-\mathrm{Bu})_{3}\right](\mathrm{Cl})(\mathbf{1})$ (Figs. 1 and 2), which crystallizes in a monoclinic system and adopts a centrosymmetric space group of $\mathrm{P} 2{ }_{1} / \mathrm{c}$. In the cation of compound $\mathbf{1}$, the central phosphorus atom has tetrahedral coordination sphere. The coordination environment of $\mathrm{P}$ atom is constituted of a chloride atom and three $\mathrm{N}$ atoms of three $\mathrm{NHt}-\mathrm{Bu}$ groups (Fig. 1). Three big $t$-Bu groups of the exterior of the cation surround the centrer of the $\mathrm{PN}_{3} \mathrm{Cl}$ tetrahedron and the cation look like a tripod structure on the whole. The anion is a $\mathrm{Cl}^{-}$and it is connected with the cation and adjacent cation with three $\mathrm{N}-\mathrm{H} \cdots \mathrm{Cl}$ hydrogen bonding interactions. One is $\mathrm{N} 1-\mathrm{H} 1 \mathrm{~A} \cdots \mathrm{Cl} 2$ bond with $\mathrm{D} \cdots \mathrm{A}$ distance of 3.220 (3) $\AA$, the second one is $\mathrm{N} 2-\mathrm{H} 2 \mathrm{~A} \cdots \mathrm{Cl} 2$ bond with D...A distance of 3.224 (3) $\AA$ and the third one is N3-H3A $\cdots \mathrm{Cl} 2$ bond with D ...A distance of 3.199(3) $\AA$. Then through these hydrogen bonding interactions, all adjacent cations and anions connect each other along $\mathrm{c}$ axis to give out of a supramolecular zig-zag like infinite chain (Fig. 2). The hydrogen bonding data of lengths and angles are in the range of ordinary examples and have been examined by the PLATON program ${ }^{15,16}$. The details of hydrogen bonding interactions are shown in Table-3.

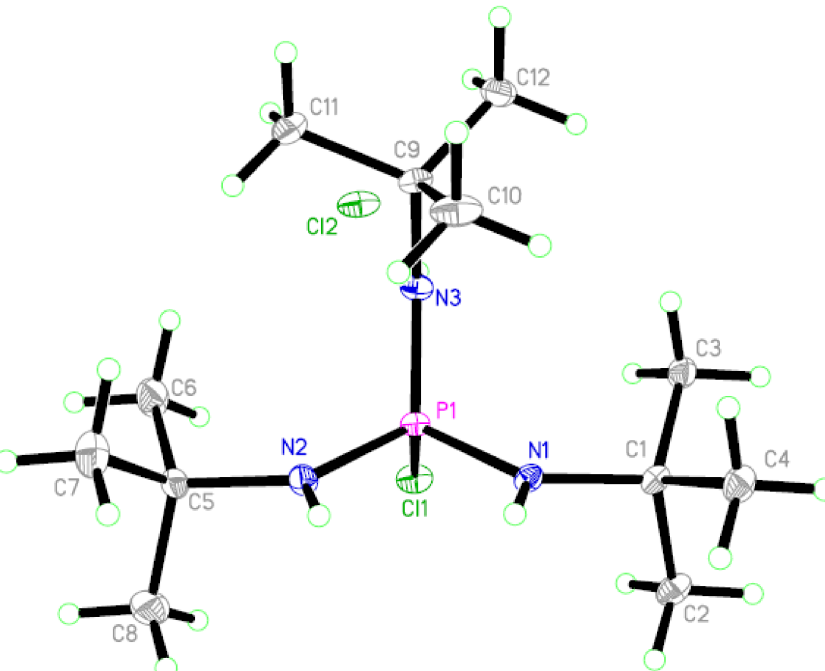

Fig. 1. Structure and labeling of the compound 1, with displacement ellipsoids drawn at the $30 \%$ probability level and $\mathrm{H}$ atoms shown as small spheres of arbitrary radii

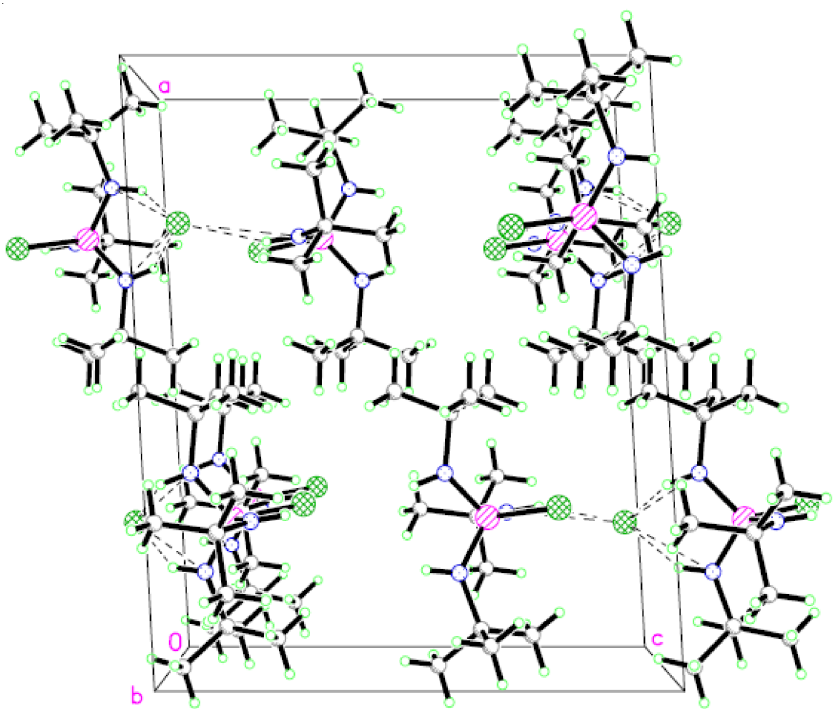

Fig. 2. Packing diagram viewed along the b-direction, the dash lines present as the hydrogen bonds. ( $\mathrm{Cl}$, green; $\mathrm{P}$, purple; $\mathrm{N}$, blue; $\mathrm{C}$, gray; $\mathrm{H}$, white)

\begin{tabular}{|c|c|c|c|c|}
\hline \multicolumn{5}{|c|}{$\begin{array}{c}\text { TABLE- } 3 \\
\text { HYDROGEN-BOND GEOMETRY }\left(\AA,{ }^{\circ}\right) \text { FOR } 1\end{array}$} \\
\hline D-H $\cdots A$ & D-H & $\mathrm{H} \cdots \mathrm{A}$ & $\mathrm{D} \cdots \mathrm{A}$ & D-H $\cdots A$ \\
\hline $\mathrm{N} 1-1 \mathrm{~A} \cdots \mathrm{Cl} 2^{\mathrm{i}}$ & $0.86(3)$ & $2.58(3)$ & $3.220(3)$ & $132(3)$ \\
\hline $\mathrm{N} 2-2 \mathrm{~A} \cdots \mathrm{Cl} 2^{\mathrm{i}}$ & $0.86(3)$ & $2.59(3)$ & $3.224(3)$ & $132(3)$ \\
\hline $\mathrm{N} 3-3 \mathrm{~A} \cdots \mathrm{Cl} 2$ & $0.86(2)$ & $2.39(2)$ & $3.199(3)$ & $158(2)$ \\
\hline C6-6A …Cl1 & $0.96(4)$ & $2.76(4)$ & $3.488(4)$ & $133(4)$ \\
\hline
\end{tabular}

\section{Conclusion}

The supramolecular compound $\left[\mathrm{ClP}(\mathrm{NHt}-\mathrm{Bu})_{3}\right](\mathrm{Cl})$ has been synthesized and characterized as a supramolecular zigzag chain structure constructed by three type of $\mathrm{N}-\mathrm{H} \cdot \cdots \mathrm{Cl}$ hydrogen bonding interactions.

\section{ACKNOWLEDGEMENTS}

The authors are grateful for the financial support from National Natural Science Foundation of China (Project Nos. 11075147 and 51002147). 


\section{REFERENCES}

1. G.M. Aspinall, M.C. Copsey, A.P. Leedham and C.A. Russell, Coord. Chem. Rev., 227, 217 (2002).

2. T. Chivers, M. Krahn, G. Schatte and M. Parvez, Inorg. Chem., 42, 3994 (2003)

3. Z. Fu and T. Chivers, Can. J. Chem., 85, 358 (2007).

4. Z.Y. Fu and T. Chivers, Inorg. Chem., 44, 7292 (2005).

5. T. Chivers, Z.Y. Fu and L.K. Thompson, Chem. Commun., 2339 (2005).

6. A.F. Armstrong, T. Chivers, M. Krahn and M. Parvez, Can. J. Chem., 83, 1768 (2005)

7. W. Chai, J. Lin, L. Song, K. Shu, L. Qin, H. Shi and J. Guo, Solid State Sci., 12, 2100 (2010).

8. W.-X. Chai, L. Song, K.-Y. Shu, H.-S. Shi and L.-S. Qin, J. Chem. Crystallogr., 40, 448 (2010).
9. W. Chai, L. Song, H. Shen and K. Shu, Phosphorus, Sulfur, Silicon Rel. Elem., 184, 3212 (2009).

10. Y. Yang, W. Chai, L. Song and K. Shu, Acta Crystallogr. E, 66, M1486 (2010).

11. J. Chen, W. Chai, L. Song, Y. Yang and F. Niu, Acta Crystallogr. E, 67, M1284 (2011)

12. C. Song, W. Chai, L. Song, Y. Yang and J. Lin, Acta Crystallogr. E, 67, M109 (2011)

13. Y. Yang, W. Chai, L. Song and J. Lin, Acta Crystallogr. C, 67, M293 (2011).

14. G.M. Sheldrick, Acta Crystallogr. A, 64, 112 (2008).

15. P. Vandersluis and A.L. Spek, Acta Crystallogr. A, 46, 194 (1990).

16. A.L. Spek, PLATON A Multipurpose Crystallographic Tool, Utrecht University: Utrecht, The Netherlands (2001). 